\title{
A Research on Business Intelligence and SME'S: Concepts, Components, Techniques
}

\author{
S.S. Bhosale, R.B. Patil
}

\begin{abstract}
Business Intelligence (BI) what's more, SMEs are unique studies areas besides increasingly unmistakable dating among the ones substances can offer the fruitful addition from each one of a kind. This affiliation has been considered in driving the advancing circumstance. This collaboration does in reality invigorate singular bits of studying of BI and SMEs, it affords to the commercial agency environmental execution. regardless of the way that evaluation on BI and SMEs is colossal thus far, restricted highlight changed into given on analyzing factor among BI and SMEs. Thusly, this assessment is intended to dismember composing and research an organized element of view of recording broke on how $B I$ and SMEs gain from every extraordinary and provides to the business enterprise natural execution. An emotional substance evaluation became driven for the manner, which considers forty three articles for information deliver. Revelations of the composition have a look at recommend improving restriction of SMEs and new improvement of BI, which may also effect each other. Disclosures of this evaluation also can turn out to be large for similarly research with regard to BI execution accomplishment.
\end{abstract}

Catchphrases enterprise insight, SMEs, alternate adjustment, potential, easy control, intuitive connection, and studying.

\section{INTRODUCTION}

Enterprise Intelligence may be portrayed as a "high-quality deal of numerical fashions and exam techniques of questioning that deliberately misuse the to be had data to recuperate data and analyzing the board useful in helping complex essential authority systems" BI, as established through Natasha et al. (2015), can be portrayed as a device becoming a member of amassed date, information gathering, and studying the board with analytical gadgets to provide complicated inner and forceful facts to coordinators and pioneers.

BI is considered as the capacity to take away the inner and out of doors statistics open to an association, for the purpose of assisting vital initiative and improving company execution. BI enables administrators through isolating statistics from numerous assets in better important authority at every key and critical measurement, for elegant use, conventional statistics systems farewell, yet for one-of-a-type leveled and valuable orchestrating; new gadgets are required for enterprise exam.

The need of SMEs informatization of the information examination as an interior is extra grounded and extra grounded informatization development of SMEs has encountered 4 crucial degrees: the head, data circulating. tries

Revised Version Manuscript Received on 16 September, 2019.

Mr. S.S. Bhosale, Research Scholar, Shri JJTU, Rajasthan, India.

(Email: sachin1978in2002@yahoo.com)

Dr. R.B. Patil., S.K.Somaiya College of Arts, Science and Commerce, Mumbai, Maharashtra, India.

(Email: patilrajendrab@gmail.com) disperse creation and facts of things with untouchable net enterprise arrange. The 2nd, constructing an

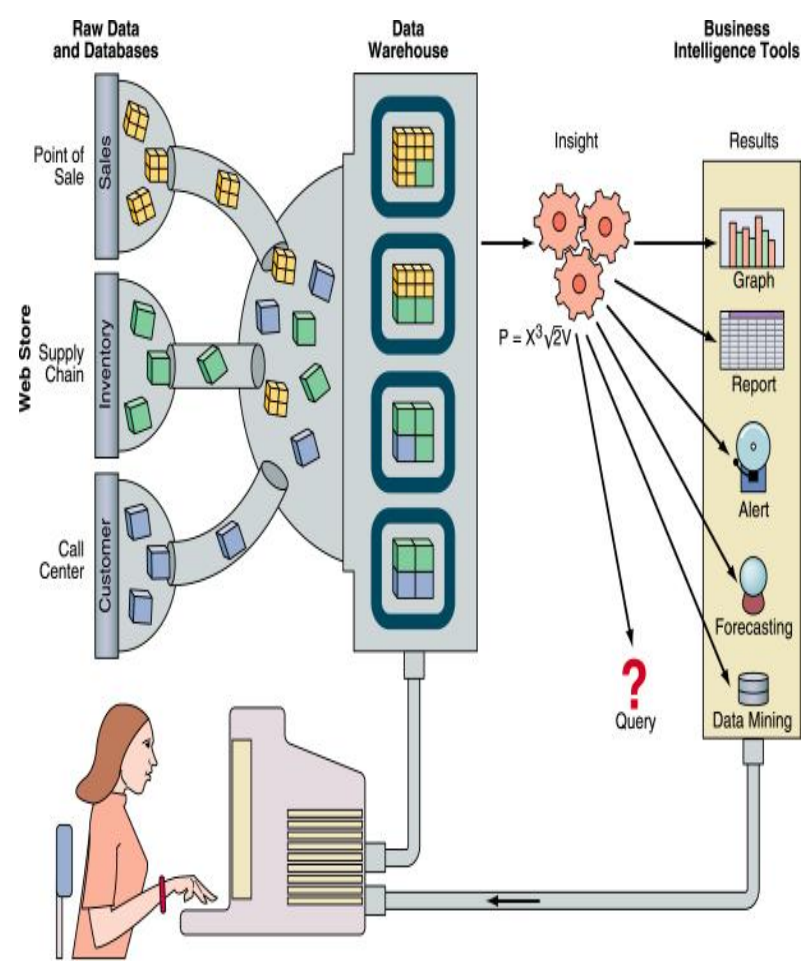

Fig 1: Architecture of BI

Independent internet web page, a free area can show the agency's popular impact what's extra, first-class, e-mail and texting framework are carried out as techniques for indoors connection and outer verbal exchange. So the degree Improves showcasing and customer responsiveness of a mission. The 0.33, SMEs take part in software administrations, accumulate simple budgetary, showcasing and authoritative diploma to perform administrative center mechanization. With the net and on line business circumstance enhancing, the level of SMEs information step by step increments. all the whilst, the statistics of SMEs facts is to an ever growing amount, the ones facts originate from the following 3 viewpoints: first of all, orders, stock, capital exchanges of the company enterprise frameworks; except, contender and employer of undertakings which clients and organizations artwork; Thirdly, specific outer situation of companies. The first-rate approach to extricate statistics from infinite, as an example, the be a part of some of the trends of different forms of customers and merchandise that they

\section{Published By:}

Blue Eyes Intelligence Engineering 
decide on to buy, may be found via the examination of offers statistics, This might be an increasingly more specific centered on enhancements or deliver more customized benefits, and so forth., those strategies make employer officers and team of workers comprehend the execution of each $2 \mathrm{~d}$ of undertakings, assist corporations find issues in time and beautify the speed and exactness of essential management; how to make increasingly a success usage of records innovation to compose total industrial company arranging, fundamental management, arranging, appearing, to accomplish the nice method of company obligations. these troubles development toward becoming bottleneck of inner and out use of SMEs information. because the market rivalry scenario getting similarly express, lower income, more prices and different issues, that are cause by way of the use of big control, have provoked severa SMEs to move the concentration from key proceeding to industrial organisation expertise, in order to reduce intake and enhance proficiency.

Stackowiak et al. (2007) represent business notion because the way in the direction of taking pretty some statistics, dissecting that information, and displaying an extraordinary kingdom set of news that collect the substance of that facts into the basis of company sports, empowering the executives to decide basic every day business corporation options. (Cui et al, 2007) see BI as way and approach for reinforcing commercial enterprise execution by means of giving great allows to respectable chief to empower them to have big data interior reach. BI devices are seemed as innovation that empowers the effectiveness of organization pastime by means of manner of giving an advanced an incentive to the task records and ultimately the way in which this information is used.

Zeng et al. (2006) symbolize BI as "The technique of accumulation, remedy and dissemination of facts that has a purpose, the lower of vulnerability genuinely taking form of each single vital desire." professionals depict business expertise as a "business organisation the executives time period used to portray packages and enhancements which might be carried out to collect, provide get proper of access to to have a examine records and information approximately an employer, on the manner to allow them to settle on better informed commercial enterprise selections." (Tvrdíková, 2007) portrays the important trademark for BI device is that it is ability to acquire information from heterogeneous source, to have increase expository strategies, and the capacity to help multi customers requests.

Zeng et al. (2006) ordered BI innovation relying at the technique for statistics conveyance; revealing, real exam, in particular appointed studies and predicative research. The idea of enterprise expertise (BI) is raised with the aid of Gartner gathering for the cause that 1996. it's miles characterized as the use of some of systems and innovations, as an instance, J2EE, DOTNET, internet Administrations, XML, information distribution middle, OLAP, statistics Mining, portrayal advancements, and so on, to enhance mission activity adequacy, bolster the board/choice to perform upper palms. business perception through these days is in no way some other innovation in vicinity of an integrated answer for businesses, internal which the commercial corporation necessity is really the essential thing issue that drives innovation development. commands to distinguish and imaginatively address key enterprise problems is on this manner constantly the large check of a BI software to perform proper corporation sway. II. component OF commercial enterprise INTELLIGENCE

OLAP (online Analytical Processing): It refers to the way by using which commercial organization customers can break up their way thru statistics the use of sensitive devices that think about the route of measurements, as an example, time or chains of command. at the internet Analytical Processing or OLAP offers multidimensional, abridged views on enterprise facts and is applied for revealing, studies, demonstrating furthermore, getting prepared for boosting the industrial agency. OLAP systems and gadgets can be utilized to art work with records distribution centers or statistics shops meant for subtle undertaking insight frameworks. these frameworks technique questions required to discover drifts and have a look at fundamental additives. Detailing programming produces gathered views of information to hold the management knowledgeable approximately the circumstance of their enterprise. other BI apparatuses are used to keep and damage down records, as an example, statistics mining and statistics stockrooms; preference assist frameworks and estimating; report stockrooms furthermore, report the board; learning the executives; mapping, facts perception furthermore, sprint boarding; the executives records frameworks, geographic statistics frameworks; trend research; software program as a carrier (SaaS).

strengthen Analytics: it's miles alluded to as information mining, figuring out or prescient examination, this exploits measurable examination strategies to count on or offer conviction measures on certainties.

company overall performance management (Portals, Scorecards, and Dashboards): This general type generally offers a holder to a few portions to plug into with the cause that the complete recounts a story. For precedent, a truthful scorecard that indicates portlets for cash related measurements joined with nation authoritative learning and development measurements.

real Time BI: It considers the ongoing conveyance of measurements through electronic mail, informing frameworks or doubtlessly smart presentations.

facts Warehouse and facts bazaars: The records distribution center is the noteworthy section of commercial enterprise expertise. it's miles scenario arranged, coordinated. The facts stockroom bolsters the bodily unfold of records thru managing the numerous task statistics for joining, purifying, and collection and inquiry assignments.

statistics or pictures furthermore, different interactive media facts.

It can also encompass the operational information which may be portrayed as an updateable path of action of fused statistics used for massive commercial business enterprise extensive important crucial authority of a selected a part of analyzing. It includes stay statistics, not portrayals, and holds beside the factor data. records assets can be operational databases, chronicled records, out of doors information for example, from marketplace ask about establishments or from

Published By:

Blue Eyes Intelligence Engineering 
the internet), or statistics from the correctly cutting-edge statistics stockroom state of affairs. The facts sources can be social databases or a few other statistics form that supports the road of enterprise applications. They moreover can harp on precise ranges additionally, can contain looked after out statistics, as an instance, tables or spreadsheets, or unstructured information, as an example, plaintext documents or images likewise, different sight and sound facts.

A data store as depicted with the aid of way of (Inmon, 1999) is a social affair of elements of facts created for choice help in perspective on the requirements of a given department. cash has their data bazaar, displaying has theirs; additionally, bargains have theirs, and so forth. Likewise, the data keep for showing simply faintly takes after a few other man or woman's statistics store.

possibly most basically, (Inmon, 1999) the person offices have the hardware, programming, facts what is more, programs that include the facts bazaar. each office has its personal virtually considered one of a type interpretation of what a statistics bazaar should resemble and every department's records save is tough to overlook to and specific to its own wishes. Like data stockrooms, facts shops consist of operational statistics that motives business masters to strategize problem to assessments of beyond examples and reviews. the important thing complexity is that the development of a facts hold relies on an unequivocal, predefined necessity for a specific assembling what's extra, plan of pick records. There may be numerous records shops internal an task. A information bazaar can assist a specific business corporation paintings, commercial enterprise technique or declare to fame unit. A information bazaar as portrayed by way of manner of (Inmon, 1999) is an aggregation of elements of records made for choice help reliant at the conditions of a given department. coins has their information shop, publicizing has theirs, likewise, deals have theirs, and so forth. moreover, the information shop for advancing simply faintly takes after a few distinct character's records save. BI mechanical assemblies are considerably identified as some different middleware between really worth primarily based programs what's gradually, selection help applications, thusly decoupling structures altered to a effective remedy of agency trades from structures redid to a compelling help of organisation choices. the limits of BI be a part of selection useful resource, online explanatory making plans, real exam, guaging, and facts mining. arising subsequent are the genuine portions that building up BI.

information sources records assets can be operational databases, obvious information, out of doors data as an instance, from measurable looking over institutions or from the net), or on the other hand records from the viably present information conveyance cognizance scenario. The facts belongings may be social databases or some distinct facts shape that helps the road of agency packages. They in addition can harp on precise levels except, can include taken care of out facts, for instance, tables or spreadsheets, or unstructured facts, as an instance, plaintext.

\section{PROBLEMS IN BI}

professional View: specialists see BI in unique techniques. facts warehousing masters maintain in mind $\mathrm{BI}$ to be worthwhile systems and are especially new to them. these experts deal with BI as development installation for selection help software. The maker is of supposition that to records mining specialists BI is ready of moved preference surely robust structures with information mining techniques and employments of figurings. To professionals BI is taken into consideration as a figuring out and multidimensional evaluation based device.

Methodologies in data Warehousing: the rule of thumb key to efficient BI gadget is becoming a member of records from a wide scope of substantial commercial enterprise operational structures into an enterprise information stockroom. All round scarcely any affiliations have an apparent project statistics conveyance consciousness. this is a result of the significant degree of effort in the direction of consolidating the whole task records. (Bersonet.Al, 2002) enhances that during context on growing particularly novel enterprise situation, handiest the most forceful endeavors will benefit bolstered market ground. The affiliations will isolate themselves by means of the usage of the capability to make use of information about their industrial corporation cognizance, clients, and undertakings to earnings thru the company openings.

investigation of proper facts: some examinations tallying Gartner, Forrester and worldwide Server domestic file that with the aid of manner of a ways most of the establishments at some point of the globe are excited about contributing in BI. it's miles to be visible that no matter real pastimes in big commercial organization useful resource orchestrating (ERP) and customer relationship the board (CRM) over the span of the today's decade institutions are endeavoring to accumulate high ground. it's miles a right away stop end result of the records gotten through the ones structures. Any organization could look ahead for one purpose called 'proper get right of entry to to records quickly'. alongside these strains, the institutions want to manual the evaluation and use of data in case you want to determine operational picks. kingdom for checking regular inventory or giving certain proposition to clients, corporations need proper get right of entry to to facts fast. completing increasingly canny industrial organization structures is the spot organization statistics outcomes and results the gauge and returns a motivation to any firm.

\section{FUNCTIONS OF BUSINESS\& RESULTS}

understanding In those all of sudden converting world purchasers are via and by way of citing quicker logically useful organisation from establishments. To live forceful institutions need to meet or outperform the needs for consumers. institutions have to depend all of the extra strongly on their industrial corporation information systems to stay before examples and destiny activities. business understanding customers are starting to call for actual time enterprise Intelligence] or close to consistent exam concerning their business organisation, particularly in cutting factor undertakings. they may for the most element assume present day-day and fresh data likewise as they display display inventory articulations at the web. Month to month 
what is frequently, even constantly examination won't contend with enterprise. in the no longer far-eliminated future institutions will decorate closer to getting to be susceptible to progressing company records in a tremendous deal vague style from human beings via and massive desire to get information on the internet in most effective a couple of ticks. furthermore soon organisation statistics will become being more democratized wherein stop customers from all through the association will probably check facts on their particular bit to see how it is appearing. Thusly, in a while, the capability requirements of commercial enterprise facts will growth inside the equal manner that customer wishes boom. it's miles as desires be vital that institutions growth at a comparative pace or essentially faster to stay forceful $\mathrm{V}$.

\section{ACKNOWLEDGMENTS}

I need to thank anybody who help me in different manner. in particular i am grateful to my publications Dr. R.B. Patil for him non-prevent guide and steering in my paintings.

\section{END}

first rate alternate arranged information frameworks are currently everyday in each real enterprise, correctly making the entirety trustworthy for companies around the world. To live aggressive, regardless of the fact that, presently calls for scientifically situated frameworks which can reform an agency's ability to rediscover and use records they correctly declare. the industrial company understanding (BI) has advanced over the preceding decade to depend progressively on ongoing facts. The BI frameworks automobile-begin sports to frameworks relying on recommendations and placing to help a few business forms. those systematic frameworks get knowledge from the abundance of records handy, conveying records that is convincing, fact based, and massive. Ventures today request rapid outcomes. it's far attending to be important in recent times that no longer exclusively is the business enterprise examination accomplished, but moreover sports in light of studies of results may be completed and without delay modifications parameters of business bureaucracy. The paper investigated the ideas of BI, its segments, blessings of BI, innovation prerequisites, making plans and executing company notion, and unique BI techniques.

\section{REFERENCES}

1. Adelman Sid, Moss Larissa and Barbusinski Les. (2002) "I placed several definitions of BI', DM overview. Retrieved 17 August 2002 from http://www.Dmreview.Com /article_sub.Cfm?ArticleId $=5700$

2. Berson Alex, Smith Stephen and Thearling Kurt. (2002) 'building records Mining programs for CRM', Tata McGraw Hill. [3]. Cui, Z., Damiani, E. And Leida, M. (2007) 'benefits of Ontologies in real Time statistics get entry to', virtual Ecosystems and technology convention, DEST '07.Pp. 392-397.

3. Curt corridor. (1999) 'facts Warehousing for enterprise Intelligence'. Retrieved 20 March 1999, from http://www.Cutter.Com/itreports/RP68E .Pdf.

4. Davenport, T.H.(1993) 'manner Innovation: Reengineering work via facts technology', Harvard business faculty Press, Boston.
5. Denison, D.R. (1997) 'in the direction of a processbased concept of organizational format: Can organizations be designed around value chains and networks?', Adv. Strategic control, 14, pp. 1-44.

6. Gangadharan.G.R. AndSwamy, N., Sundaravalli. (2004) 'commercial enterprise Intelligence systems: layout and Implementation techniques', court cases of twenty 6th international convention on records era Interfaces, Cavtat, Croatia. Retrieved 15 March, 2007 from http://ieeexplore.Ieee.Org/ xpls/abs_all.Jsp?Arnumber $=1372391$

7. Goebel Michael and Le Gruenwald (1999), 'A survey of data mining and understanding discovery software equipment', quantity 1 , trouble 1 (June 1999) publisher ACM new york, the big apple, united states of america .

8. GolfarelliMatteo, Rizzi Stefano and CellaLuris. (2004) 'beyond records Warehousing: What's subsequent in commercial enterprise Intelligence?' lawsuits of DOLAP-04, Washington, DC, usa. Retrieved may additionally 172006 from www.Acm.Org

9. Inmon, W.H. (1999) 'building the Operational facts store', Wiley PublishersNew York, 2nd model.

10. Malhotra, Y. (2000) 'statistics manipulate to expertise management: beyond "hi-Tech Hidebound" structures', in Srikantaiah, T. k. And Koenig, M.E.D. (Eds.) understanding control, Medford, NJ.

11. Nguyen ThoManh, Schiefer Josef and Min Tjoa, A. (2005) 'information warehouse format 2: feel \& reaction carrier structure (SARESA): an approach within the direction of a actual-time business intelligence solution and its use for a fraud detection utility', proceedings of the eighth ACM worldwide workshop on records warehousing and OLAP, DOLAP '05, ACM Press.

12. Stackowiak, R., Rayman, J. And Greenwald, R. (2007) 'Oracle facts Warehousing and business Intelligence solutions', Wiley Publishing, Inc, Indianapolis.

13. SuefertAndhreas and Schiefer Josef. (2005) 'better commercial enterprise Intelligence assisting business techniques with real Time commercial enterprise Analytics', court cases of the sixteenth worldwide workshop on Database and expert system applications-DEXA'05. Retrieved 19 June 2006 from www.Ieee.Org.

14. Tvrdikova, M. (2007), 'aid of decision Making thru business Intelligence gear', pc facts structures

15. Framework for privateness keeping class in statistics Mining ,DYK Sharma, GM Sharif, magazine of emerging technology and revolutionary studies 5 (nine), 178-183

16. performance assessment of put off Tolerant Networks Routing Protocols underneath various Time of live, VK Samyal, DYK Sharma worldwide journal of develop studies in computer science (IJARCS) eight

17. $\mathrm{Li}-\mathrm{Fi}$ the most latest Innovation in wireless communication S Saini, DYK Sharma international journal of advanced research in computer technology and software program.

18. internet web page category on news Feeds using Hybrid technique for Extraction advert Patel, DYK Sharma statistics \&communique era for intelligent device 107 (6), 399-405.

19. effect of buffer length on extraordinary drop policies (DLR, MOFO and E-Drop) for MaxProp Routing Protocol in DTN VK Samyal, DYK Sharma worldwide magazine of studies in implemented technological know-how \& Engineering

20. a practical evaluation of pressure and performance testing technology for web based totally programs P sonkari, 
DYK Sharma IEEE, Amity global conference on artificial Intelligence (AICAI), 399-403

21. impact of network Load and node Mobility at the general performance of Proactive, Reactive and Hybrid routing protocols of MANET V Singla, YK Sharma global journal of advanced studies in pc science 8 (three

22. analysis of selfish Node behavior in delay Tolerant Networks Routing Protocols VK Samyal, DYK Sharma global magazine of revolutionary studies in science and Engineering

23. significance look at $\mathrm{OF}$ consumer internet access statistics MINING FOR enterprise INTELLIGENCE, advert Vyas, YK Sharma Indian magazine of implemented research

24. A comprehensive observe $\mathrm{ON}$ classification $\mathrm{OF}$ automated CATEGORIZATION OF net websites: A PROPOSED method DA Vyas, DYK Sharma INDIAN magazine OF implemented research (IJAR)

25. using Open $\mathrm{CV}$ for machine getting to know in actual Time pc imaginative and prescient and picture ProcessingP S, YK SharmaInternational magazine of latest technology and Engineering 